Research Article

\title{
Drug utilization study of antihypertensive drugs in a clinic in Malaysia
}

\author{
Heethal Jaiprakash*, Vinotini K, Vindiya, Vsalni, Vikneshwara, Vigneswaran, \\ Vinosha, Voon C. Min
}

Faculty of Medicine, MAHSA

University, Jalan Elmu Off Jalan

University, Kuala Lumpur-

59100, Malaysia

Received: 3 May 2013

Accepted: 24 May 2013

*Correspondence to:

Dr. Heethal Jaiprakash,

Email: heethaljp@gmail.com

(C) 2013 Jaiprakash $\mathrm{H}$ et al. This

is an open-access article

distributed under the terms of

the Creative Commons

Attribution License, which

permits unrestricted use,

distribution, and reproduction in

any medium, provided the

original work is properly cited.

\begin{abstract}
Background: Hypertension is one of the common chronic diseases resulting in high mortality and morbidity. A plethora of new drugs are now available, and the quality of life for these patients has been altered for the better. Not many studies are conducted in Malaysia regarding drug utilization of antihypertensives and hence this study was planned.

Methods: This was a pilot study conducted in a private clinic in Kuala Lumpur. Thirty patients with hypertension were chosen randomly and their prescriptions were analyzed. The data was collected in a proforma designed for the study. The proforma included variables such as age, gender, drugs used, and also regarding the names of the drugs used (generic or trade). The data was analyzed using descriptive statistics.

Results: Thirty patients were recruited for the study. We found that $53 \%$ of the patients were females and $47 \%$ males. Trade names were more commonly used i.e. $64 \%$ of patients, than the generic names. Monotherapy $(70 \%)$ was more frequently used than combination drugs. Beta blockers $(45 \%)$ were used more often followed by calcium channel blockers $(25 \%)$.

Conclusions: The incidence of polypharmacy was low. The three most common groups of drugs used in hypertension were beta blockers followed by calcium channel blockers and then angiotensin converting enzyme inhibitors. Drug utilization studies are powerful exploratory tools to ascertain the role of drugs in society.
\end{abstract}

Keywords: Drug utilization, Hypertension, Antihypertensive drugs

\section{INTRODUCTION}

Hypertension is estimated to cause $4.5 \%$ of the global disease burden. It is a significant risk factor for cardiovascular morbidity and mortality. It can lead to stroke, myocardial infarction, blindness and renal failure. The national prevalence of hypertension in Malaysia based on the national health and morbidity survey (NHMS) III in 2012 was 32.2\%. ${ }^{1}$ The projected prevalence of hypertension 2020 is $35.8 \%$ which is about 7.6 million Malaysians. With this projected increase in the prevalence of hypertension, the number of drugs prescribed, morbidity and mortality would also increase. A plethora of new drugs are now available, and the quality of life for these patients has been altered for the better. The fundamental goal of treatment should be the prevention of the important endpoints of hypertension. The choice of more expensive agents were cheaper one would be equally effective may have a negative impact on the national healthcare budget. Therefore drug utilization studies which evaluate the medical, social and economic outcome of drug therapy is useful. ${ }^{2}$

Drug utilization research was defined by WHO in 1977 as the marketing, distribution, prescription, and use of drugs in a society, with special emphasis on the resulting medical, social and economic consequences. ${ }^{3}$ Drug utilization research was developed by the spark initiative taken during the mid 1960 in the United Kingdom and Northern Europe. ${ }^{4}$ The revolutionary work by Arthur Engle in Sweden and Pieter Siderius in Holland comparing drug utilization between different countries 
and regions alerted many investigators the importance of it. ${ }^{5}$ It observes the prescribing attitudes of physicians with the aim to provide drugs rationally. ${ }^{6,7}$ Research in this field aims to analyze the present state and the developmental trends, of drug usage at various levels of the health care system, whether national, regional, local or institutional. Drug utilization studies may evaluate drug use at a population level, according to age, sex, social class, morbidity, among other characteristics. ${ }^{8}$

The study aims at finding the utilization pattern of antihypertensives in an outpatient clinic. The present study was conducted in order to know the current trend in the prescription of antihypertensive drugs in Kuala Lumpur as not many studies have been conducted in this regard. This kind of studies highlights the lacunae in the present prescribing practice of physicians and helps in improving the health care of the country.

\section{METHODS}

A pilot study was carried out in a private clinic in Kuala Lumpur, Malaysia. Consent was taken from the doctor incharge of the clinic before starting the study. Thirty patients with hypertension were chosen randomly and their prescriptions were analyzed. We used the following criteria for the study:

\section{Inclusion Criteria:}

1. Patients diagnosed with hypertension according to the JNC guidelines with no other co morbid conditions.

2. Patients of either gender.

3. Patients above 18 years of age.

\section{Exclusion Criteria:}

1. Patients with other co morbid conditions.

2. Patients who did not receive antihypertensive treatment.

3. Patients below 18 years of age.

The data was collected in a pre-designed proforma designed for the study. The proforma included variables such as age, sex, drugs used, and whether the names of the drugs used in the prescription were generic or trade. The data was analyzed using descriptive statistics.

\section{RESULTS}

A total of 30 patients who met the inclusion criteria were included in the study.

As shown in figure 1 we found that there were more females than males in our study.

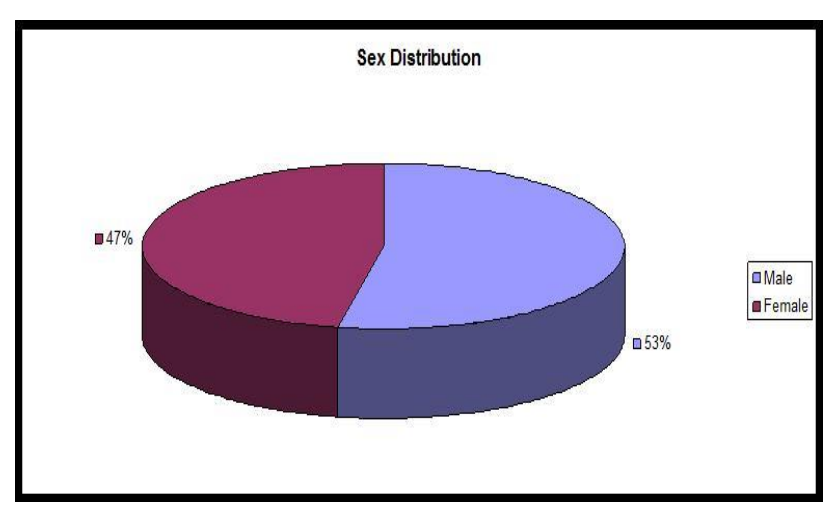

Figure 1: Sex distribution.

Table 1: Age distribution.

\begin{tabular}{|llll|}
\hline $\begin{array}{l}\text { Range } \\
\text { (years) }\end{array}$ & Male & Female & Total \\
\hline $\mathbf{3 1 - 4 0}$ & $4(25 \%)$ & $4(29 \%)$ & $8(27 \%)$ \\
\hline $\mathbf{4 1 - 5 0}$ & $4(25 \%)$ & $2(14 \%)$ & $6(20 \%)$ \\
\hline $\mathbf{5 1 - 6 0}$ & $8(50 \%)$ & $6(43 \%)$ & $14(47 \%)$ \\
\hline $\mathbf{6 1 - 7 0}$ & - & $1(7 \%)$ & $1(3 \%)$ \\
\hline $\mathbf{7 1 - 8 0}$ & - & $1(7 \%)$ & $1(3 \%)$ \\
\hline
\end{tabular}

As seen in table 1 most of the patients were in the age group of 51-60 years (47\%). When we analyzed the age distribution with respect to the gender we found the same result i.e. 51-60 years.

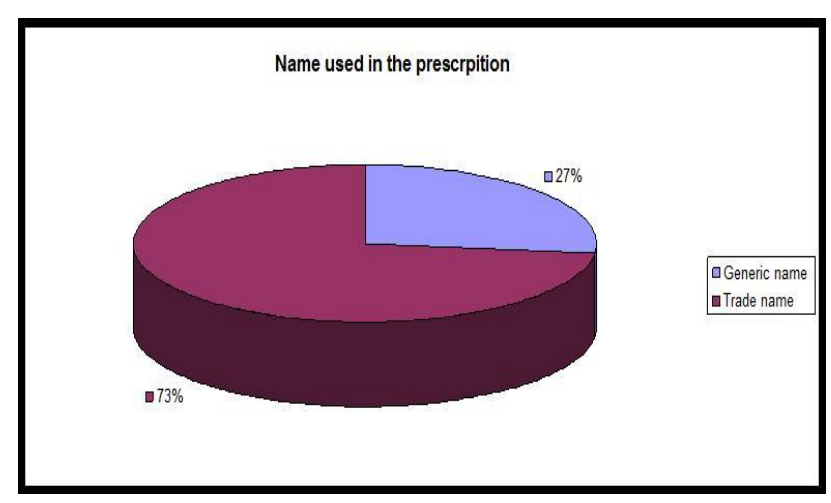

Figure 2: Name used in the prescription.

It was observed that most of the prescriptions had trade names $(73 \%)$ as seen in figure 2 .

As shown in figure 3 it was observed that monotherapy was the common prescribing pattern $(70 \%)$. 


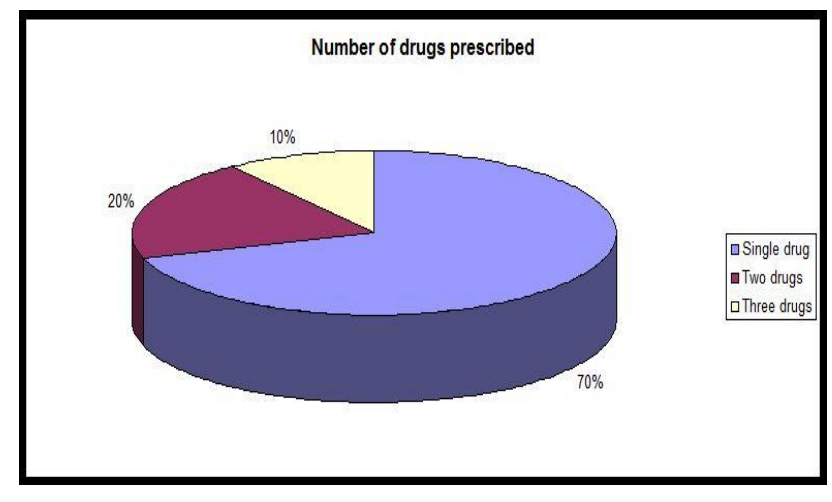

Figure 3: Number of drugs prescribed.

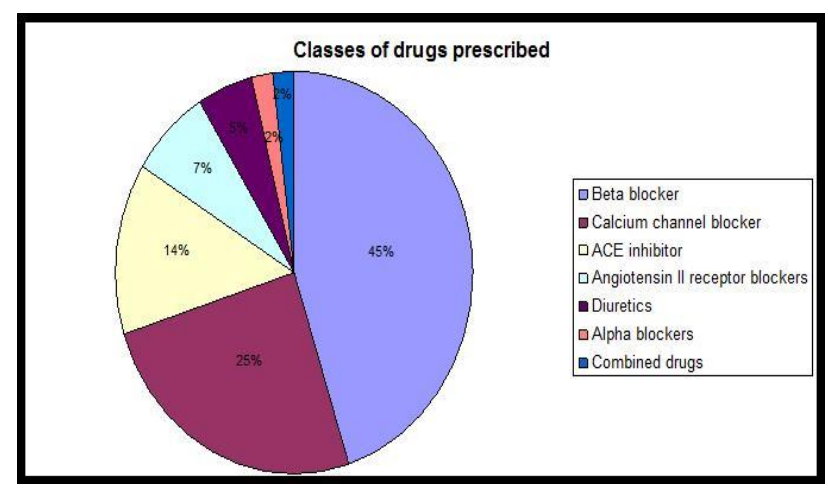

Figure 4: Classes of drugs prescribed.

From figure 4 we observe that the commonly prescribed drugs were beta blockers (45\%) followed by calcium channel blockers $(25 \%)$. The least prescribed drugs were alpha blockers and combined drugs (2\%).

We observed that among the beta blockers atenolol was commonly used. In case of calcium channel blockers it was only amlodipine used in all the cases. Perindopril was the ACE inhibitor frequently prescribed and irbesartan in case of angiotensin receptor blockers. Among the alpha blockers it was prazosin and diuretics it was hydrochlorothiazide. The combination drug included hydrochlorothiazide and irbesartan.

\section{DISCUSSION}

Drug utilization studies are powerful exploratory tools to ascertain the role of drugs in society. ${ }^{9}$ They create a sound sociomedical and health economic basis for health care decision making. ${ }^{10}$ It is one of the most effective methods to assess the prescribing pattern of physicians. ${ }^{11}$

In our study we observed that hypertension was more prevalent in females than in males which was in concurrence with the study conducted by $\mathrm{H}$ Tiwari et al. ${ }^{2}$ Most of the patients were in the age group of 51-60 years among both the genders. This could be due to the fact that hypertension is very common in this age group. The above observation was also noticed in a study conducted in India by Hari Babu et al. ${ }^{12}$
It was observed that the physician used trade names frequently in the prescription which was not the same in other studies. ${ }^{2}$ If generic names were used it could decrease the financial burden on the patient. ${ }^{13}$ Monotherapy was commonly used which reduced the incidence of adverse effect and also the cost for the patient. As in other studies beta blockers were commonly prescribed and atenolol was the beta blocker used for most patients. ${ }^{12}$ This could be due to the fact that beta blockers do not cause reflex tachycardia like calcium channel blockers and atenolol is cardio selective. The adverse effect profile of beta blockers is better than calcium channel blockers.

According to the treatment guidelines by the academy of medicine in Malaysia diuretics are generally recommended as the first-line therapy for treatment of hypertension without co morbid conditions. Diuretics were one of the least prescribed drugs in our study which contradicts the standard guidelines for the treatment of hypertension. This could be due to its effect on the glucose homeostasis and lipid profile as most of our patients were in the elderly age group. ${ }^{14}$ Based on the above baseline data more studies are recommended in bigger hospitals. Especially the hospitals attached to public universities, to have a better picture of the drug utilization pattern in the country. This would improve the treatment strategies in the management of hypertension and also help in the effective use of the health care budget.

In this study we found that beta blockers were the commonly prescribed drugs. Polypharmacy was low. Trade names were commonly used which increased the cost of treatment for the patient. The antihypertensives where not used according to the standard guidelines which indicate that there were no rational drug prescription. Our study provides just the baseline data. We recommend more such studies with more parameters of analysis to provide regular feedback to physicians and health care personnels. This can lead to rationale drug prescribing pattern for hypertension.

\section{ACKNOWLEDGEMENTS}

We would like to thank our former Dean Prof Dato' Dr Khairul Anuar Abdullah and the present Dean Prof Dr Abdul Rahim Md. Noor for supporting us in doing this study. We would also like to thank the doctor incharge of the clinic where the study was conducted and also the patients who participated in the study.

Funding: No funding sources

Conflict of interests: None declared

Ethical approval: Not Required

\section{REFERENCES}

1. Tee SR, Teoh XY, Wan Mohd Aiman WAR, et al. The Prevalence of Hypertension and its associated 
risk factors in two rural communities in Penang, Malaysia. IeJSME 2010;2:27-40

2. Tiwari H, Kumar A, Kulakarni SK. Prescription monitoring of anti-hypertensive drug utilization at the panjab university health centre in India. Singapore Med J 2004; 45: 117-120.

3. WHO Expert Committee. The Selection of Essential Drugs, technical Report Series no.615. Geneva: World Health Organization, 1977.

4. Wade O. Drug utilization studies: Implications for medical care. Acta Medica Scandinavica 1984; Suppl 683:7-9.

5. Engel A, Siderius P. The consumption of drugs; a report on a study 1966-1967. Copenhagen: WHO regional office for Europe, 1968.

6. Kapoor K, Raina RK, Kapoor S. Drug prescribing pattern in a teaching hospital. Indian $\mathbf{J}$ Pharmacol 1985;17:168.

7. Pradhan SC, Shewade DG, Shashindaran CH, Bapna JS. Drug Utilization studies. National Med J India 1988;1:185-9.

8. Helena G. Drug Utilization studies. Arquivos de Medicina 2008;22:69-74.

9. Sutharson L,Hariharan RS, Vamsadhara C.Drug utilization study in diabetology outpatient setting of a tertiary hospital. Indian J Pharmacol 2003;35:237-38.
10. Bakssas I, Lunde P KM. National drug policies: the need for drug utilization studies. Trends Pharmacol Sci 1986;7:331.

11. Yuen YH, Chang S, Chong CK, Lee SC, Critchley JA, Chan JC. Drug utilization in hospital general medical outpatient Clinic with particular reference to antihypertensive and antidiabetic drugs. J Clin Pharm Ther 1998;23:287-94.

12. Haribabu R, Manasa Reddy, Vidyadhar S. Drug utilization of antihypertensive agents in an urban primary health care center in south India. International Journal of innovative pharmaceutical research 2012;3:244-6.

13. Tasneem S, Fouzia N. Drug utilization study in ischemic heart diseases associated with diabetes and hypertension. International Journal of Pharma and Biosciences 2010;1:1-4.

14. Prisant LM, Beall SP, Nichoalds GE, Feldman EB, Carr AA, Feldman DS, Hames CG. Biochemical, endocrine and mineral effects of indapamide in black women. J Clin Pharmacol 1990;30:121-6.

doi:10.5455/2319-2003.ijbcp20130812

Cite this article as: Jaiprakash $\mathrm{H}, \mathrm{K}$ Vinotini,

Vindiya, Vsalni, Vikneshwara, Vigneswaran,

Vinosha, Min VC. Drug utilization study of

antihypertensive drugs in a clinic in Malaysia. Int $\mathbf{J}$

Basic Clin Pharmacol 2013;2:407-10. 